\title{
Manganese-Induced Hydroxyl Radical Formation in Rat Striatum Is Not Attenuated by Dopamine Depletion or Iron Chelation in Vivo
}

\author{
W. N. Sloot,* J . Korf,† J . F. Koster,† L. E. A. De Wit,‡ and J . B. P. Gramsbergen§ \\ *TNO Nutrition and Food Research Institute, TNO Division of Analytical Sciences, Department of Bio-Pharmaceutical Analysis, P.O. Box 360, 3700 \\ AJ Zeist; †Academic Hospital Groningen, Psychiatric University Clinic, Department of Biological Psychiatry, P.O. Box $30.001,9700$ RB \\ Groningen; łE rasmus University Rotterdam, Department of Biochemistry, P.O. Box 1738, 3000 DR Rotterdam; and §TNO \\ Prins Maurits Laboratory, Research Group Pharmacology, P.O. Box 45, 2280 AA Rijswijk, The Netherlands
}

The present studies were aimed at investigating the possible roles of dopamine (DA) and iron in production of hydroxyl radicals ( $\mathrm{OH}$ ) in rat striatum after $\mathrm{Mn}^{2+}$ intoxication. For this purpose, DA depletions were assessed concomitant with in vivo 2,3- and 2,5-dihydroxybenzoic acid (DHBA) formation from the reaction of salicylate with $\mathrm{OH}$, of which 2,3-DHBA is a nonenzymatic adduct. Following intrastriatal $\mathrm{Mn}^{2+}$ injection, marked 2,3-DHBA increases were observed in a time- and dose-dependent fashion reaching maximum levels at 6-18 $\mathrm{h}$ and a plateau beyond $0.4 \mu \mathrm{mol}$ (fourfold increase). The delayed increase of 2,3-DHBA levels suggests that $\mathrm{Mn}^{2+}$ induces $\mathrm{OH}$ formation in the living brain by an indirect process. The early DA depletion ( $2 \mathrm{~h}$ ) and relatively late $\mathrm{OH}$ formation (6 h) indicate independent processes by $\mathrm{Mn}^{2+}$. In addition, depletion of DA (about $90 \%$ ) by reserpine pretreatment did not significantly alter $\mathrm{Mn}^{2+}$-induced 2,3-DHBA formation or the extent of DA depletion, suggesting that DA or DA autoxidation are not participating in $\mathrm{Mn}^{2+}$ induced $\mathrm{OH}$ formation in vivo. Furthermore, $\mathrm{Mn}^{2+}$ injection did not significantly alter the low molecular weight iron pool in striatum, and co-injections of the iron-chelator deferoxamine with $\mathrm{Mn}^{2+}$ into striatum did not significantly attenuate $\mathrm{Mn}^{2+}$-induced 2,3-DHBA formation. These findings suggest no role of chelatable iron in generation of $\mathrm{Mn}^{2+-i n d u c e d ~} \mathrm{OH}$, but do not exclude a role for mitochondrial heme-iron or peroxynitrite (Fe-independent) in $\mathrm{Mn}^{2+}$-induced $\mathrm{OH}$ formation. 1996 Academic Press, Inc.

\section{INTRODUCTION}

Chronic inhalation of manganese $(\mathrm{Mn})$ dust or vapor in humans and monkeys causes parkinsonism and dystonia $(3,4,17)$ and produces sel ective neuropathology in the basal ganglia with lesions being localized both pre- and postsynaptically to the dopaminergic (DA) nigrostriatal pathway (8, 19-21, 62, 63). In addition, $\mathrm{Mn}^{2+}$ injection into the basal ganglia of rats $(8,40$, $46,47,54)$ provides a model of chronic systemic $\mathrm{Mn}$ exposure in humans. For more than a decade, it has been hypothesized from in vitro studies that $\mathrm{Mn}$ neurotoxicity is mediated by free radicals via enhanced nonenzymatic autoxidation of catecholamines $(1,26$, $27,30,42$ ) or production of 6-hydroxydopamine (6OHDA) $(12,13,23)$. Both processes would lead to production of toxic (semi)quinones and enhanced levels of $\mathrm{H}_{2} \mathrm{O}_{2}$ and superoxide anion radicals $\left(\mathrm{O}_{2}{ }^{--}\right)$as well as hydroxyl radicals $(\mathrm{OH})$. This concept is in agreement with attenuation of $\mathrm{Mn}^{2+}$-induced $\mathrm{DA}$ depletion by vitamin $\mathrm{E}$ treatment (48). On the other hand, it has been reported that lipid peroxidation is inhibited by $\mathrm{Mn}^{2+}$ both in vitro $(11,60)$ and in postmortem brain tissues of $\mathrm{Mn}^{2+}$-exposed rats $(16,53)$. In addition, in vitro studies have shown that $\mathrm{Mn}$ produces irreversible DA depletion by oxidation to quinones without the formation of reactive oxygen species $(1,51)$.

Although production of (semi)quinones or free oxygen radicals after $M n$ has not been reported in vivo, it seems likely that DA plays a role in $\mathrm{Mn}$ neurotoxicity. For instance, pretreatment with the DA synthesis blockers $\alpha$-methyltyrosine and lisuride attenuates the neurotoxicity of $\mathrm{Mn}^{2+}(47)$, whereas the monoamine oxidase inhibitor pargyline and L-DOPA (+carbidopa) potentiate its toxicity (46).

Besides DA, brain iron could mediate neurotoxic effects of $\mathrm{Mn}^{2+}$. The selective accumulation of $\mathrm{Mn}^{2+}$ in the basal ganglia $(19,41,45)$ and anterograde axonal transport of $\mathrm{Mn}^{2+}$ in nigrostriatal and striatonigral neurons (55) may be dependent on iron transport and storage pathways $(2,6,32,33,44)$. In vitro studies have shown that $\mathrm{Mn}$ binds to the iron transport protein transferrin and its receptor on catecholamine-containing neuroblastoma cells and that $\mathrm{Mn}$-like $\mathrm{Fe}$-is internalized followed by storageintoferritin (59). There fore, $\mathrm{Mn}^{2+}$ may (in)directly liberate endogenous iron by disturbing iron homeostasis, particularly in mitochondria. In these organelles, $\mathrm{Mn}^{2+}$ induces decreased gluthatione (GSH) contents and GSH enzyme activities (38), thereby compromising a major cellular defense mechanism against oxyradicals. In addition, $\mathrm{Mn}^{2+}$ has been reported to impair ATP production, decrease 
respiratory cytochrome contents, inhibit oxidative phosphorylation, and increase lactate production $(9,39,25)$.

The aim of the present studies was twofold. First, time and dose-dependent $\mathrm{OH}$ formation by $\mathrm{Mn}^{2+}$ was assessed in relation to DA and serotonin (5-HT) depletions in order to examine whether $\mathrm{OH}$ generation is cause or consequence of brain damage. Like DA, 5-HT levels are depleted by $\mathrm{Mn}$ within the choosen time span of $24 \mathrm{~h}$ (54), which may significantly contribute to the formation of both quinones and free oxyradicals (43). In this study we used salicylate (SA) as an $\mathrm{OH}$-trapping agent, which forms the stable adducts 2,3- and 2,5dihydroxybenzoates (DHBA) $(35,56$ and references therein), and microinjections of $\mathrm{Mn}^{2+}$ into rat striatum as described previously (55). Since it has been reported that 2,5-DHBA can also be formed via P450 enzymes, which is not the case for 2,3-DHBA, the latter is a more reliable index for $\mathrm{OH}$ formation (35). Second, the roles of $\mathrm{DA}$ and iron in generating $\mathrm{Mn}^{2+}$-induced $\mathrm{OH}$ formation were investigated by analyzing 2,3-DHBA levels in striata of reserpine-pretreated (DA-depleted) or deferoxamine-treated (iron-chelated) rats, as well as by assessing different endogenous iron pools in $\mathrm{Mn}^{2+}$. injected striata.

\section{MATERIAL AND METHODS}

\section{Animals}

Wistar-derived male rats (WAG, Harlan, Zeist, The Netherlands) were kept on a 12/12-h light/dark cycle and housed in a room with a humidity of $50-70 \%$ and a temperature of $24^{\circ} \mathrm{C}$ with free access to water and chow food. Animal experimentation protocols were approved by the Ethical Committee for Laboratory Animals Experiments, TNO/Regio West (Woudenberg, The Netherlands, Reg. No. 56-3A).

\section{Materials}

$\mathrm{MnCl}_{2}$ (>96\% pure), $\mathrm{FeCl}_{2} \cdot 4 \mathrm{H}_{2} \mathrm{O}$ (>99\% pure), $\mathrm{MgCl}_{2} \cdot 6 \mathrm{H}_{2} \mathrm{O}$, and dopamine(3-hydroxytyramine $\cdot \mathrm{HCl}$ ) were obtained from Merck (Darmstadt, Germany). Solutions of metals were made as described previously (55). All other compounds were purchased from Sigma (Brunschwig Chemie, Amsterdam, The Netherlands) and stored according to the description of the manufacturer.

\section{Experimental Groups}

Chloralhydrate-anesthetized (400 mg/kg ip) rats (190$230 \mathrm{~g}$ ) received unilateral injections of $\mathrm{MnCl}_{2}, \mathrm{FeCl}_{2}$, or $\mathrm{MgCl}_{2}$ in $1 \mu \mathrm{l}$ of Milli-Q water (Millipore, Molsheim, F rance) into striatum using stereotaxic procedures as described previously (55).

DHBA formation by $\mathrm{Mn}$ : Time course and dose dependency. Two, six, or eighteen hours after intra- striatal injection of $0.4 \mu \mathrm{mol} \mathrm{Mn}^{2+}$, or $6 \mathrm{~h}$ after injection of $0.4 \mu \mathrm{mol} \mathrm{Mg}^{2+}$, rats ( $\mathrm{n}=6-7$ per group) were decapitated to dissect striatal tissues from the brain. Likewise, rats ( $n=6-7$ per dose) were injected with 0.13 or $1.20 \mu \mathrm{mol} \mathrm{Mn^{2+ }} 6 \mathrm{~h}$ before collection of their striata. In addition, $2 \mathrm{~h}$ prior to sacrifice, rats were loaded with $300 \mathrm{mg} / \mathrm{kg}$ SA (ip), whereas others (6-8 striata per group) did not receive SA to serve as negative controls.

DHBA formation by $\mathrm{Mn}$ after dopamine depletion. Eight rats were depleted of dopamine by 24 -h pretreatment with reserpine $(10 ; 2.5 \mathrm{mg} / \mathrm{kg}$ ip). These rats received a unilateral injection of $0.4 \mu \mathrm{mol} \mathrm{Mn}^{2+}$ into striatum and were decapitated $6 \mathrm{~h}$ later. In addition, SA (300 mg/kg ip) was given $2 \mathrm{~h}$ before sacrifice.

Effect of $\mathrm{Mn}$ on total and low molecular weight (LMW) iron levels. Six hours after bilateral injection of $0.4 \mu \mathrm{mol} \mathrm{Mn}^{2+}, \mathrm{Mg}^{2+}$, or $\mathrm{Fe}^{2+}$ into striatum, rats ( $n=4-8$ per treatment) were decapitated and their striata were dissected for immediate assay of total and LMW iron contents.

Effect of deferoxamineon $\mathrm{Mn}$ neurotoxicity. Ten rats received an injection ( $1 \mu \mathrm{l}$ total) of $0.4 \mu \mathrm{mol} \mathrm{Mn}^{2+}$ plus 0.2 or $2.0 \mathrm{nmol}$ deferoxamine mesylate (Desferal; DFX) into the left striatum and $0.4 \mu \mathrm{mol} \mathrm{NaCl}$ plus DFX into the right striatum. Six control rats received similar bilateral injections without DFX. All rats were loaded with SA (300 mg/kg ip) and sacrificed respectively 4 and $6 \mathrm{~h}$ after stereotaxic injection.

\section{Collection of Samples}

Collection and handling of samples for analysis of DA, 5-HT, SA, and related metabolites was done as described previously (56). Briefly, dissected striatal tissues (20-40 mg wet wt) were immediately frozen on dry ice and stored at $-70^{\circ} \mathrm{C}$. At the day of analysis, striata were sonicated in ice-cold $200 \mu \mathrm{l}$ perchloric acid containing $\mathrm{Na}_{2} \mathrm{~S}_{2} \mathrm{O}_{5}$, centrifuged, diluted with mobilephase buffer, and kept on ice before injection into the HPLC system.

For analysis of iron, freshly dissected striatal tissues were immediately weighed in preweighed potter tubes, homogenized in $100 \mathrm{mM}$ Tris/ $\mathrm{HCl}$ buffer $(\mathrm{pH} \mathrm{7.4,20 \%}$ $w / v)$, and subsequently DFX (2 mM final concentration) was added as described previously for heart tissue (61). Depending on expected concentrations, striatal tissues of 1 or 2 rats were pool ed before homogenizing.

Analysis of 6-Hydroxydopamine, Dopamine, Serotonin, Salicylate, and Related Metabolites

Levels of SA, 2,3- and 2,5-DHBA, as well as 6-OHDA, DA, 5-HT, and their metabol ites DOPAC (3,4-dihydroxyphenylacetic acid), HVA (4-hydroxy-3-methoxyphenylacetic acid), and 5-HIAA (5-hydroxyindole-3-acetic acid) were determined in striatal tissues according to a previously described HPLC procedure with UV absor- 
bance and electrochemical detection (56). Since6-OHDA standards had a retention time between 2,3- and 2,5-DHBA standards, 6-OHDA measurements were conducted in samples without SA with a detection limit of about $50 \mathrm{fmol}$. Briefly, a Spherisorb ODS2 cartridge analytical column (100 × $4.6 \mathrm{~mm}, 3 \mu \mathrm{m})$ with a ODS1 precolumn $(30 \times 4.6 \mathrm{~mm}, 5 \mu \mathrm{m})$ (Phase Separation, Ltd., Deeside, UK) was used to separate the compounds of interest at a flow rate of $0.8 \mathrm{ml} / \mathrm{min}$. The mobilephase buffer consisted of $0.1 \mathrm{M}$ sodium acetate, $6.0 \%$ methanol, $19.5 \mathrm{mg} / \mathrm{liter}$ n-octyl sodium sulfate (Merck, Darmstadt, Germany), and 10-15 mg/liter $\mathrm{Na}_{2}$ ethylenediaminetetraacetate (EDTA) dissolved in Milli-Q water and adjusted to $\mathrm{pH} 4.1$ with glacial acetic acid. Stock solutions of standards $(\sim 1 \mathrm{mM})$ dissolved in $50 \mathrm{mM}$ $\mathrm{HCl}$ containing $0.20 \mathrm{~g} / \mathrm{liter} \mathrm{Na}_{2} \mathrm{~S}_{2} \mathrm{O}_{5}$ and $0.050 \mathrm{~g} / \mathrm{liter}$ $\mathrm{Na}_{2}$ EDTA were stable for at least 2 months if kept stored in the dark at $4^{\circ} \mathrm{C}$.

\section{Analyses of Total and Low Mol ecular Weight I ron Pools}

After centrifuging the striatal homogenate at $10,000 \mathrm{~g}$ for $15 \mathrm{~min}$, the supernatant was removed for LMW iron measurements in presence of the hexadentate iron chelator DFX (61), which forms a strong complex with iron: ferrioxamine (FX). LMW iron assays were conducted under physiological or reducing conditions by adding ascorbic acid ( $20 \mathrm{mg} / \mathrm{ml}$ in solid state). Ascorbic acid was used to reduce iron from its ferric to its ferrous state, thereby liberating iron from $\mathrm{Fe}^{3+}$ complexes, resulting in total LMW iron measurements. Briefly, samples were incubated for $60 \mathrm{~min}$ at $37^{\circ} \mathrm{C}$ and prepurified by passing them through a 50-mg Extract-Clean C18 column (Alltech) on which DFX and FX are retained. After washing with $0.3 \mathrm{ml}$ water and elution with $0.2 \mathrm{ml} 90 \%$ methanol/10\% water, the eluate was injected into the HPLC system, which was equipped with an ODS2 analytical column (as mentioned above) and two variable wavel ength detectors to all ow simultaneous detection of FX at $430 \mathrm{~nm}$ and DFX at $229 \mathrm{~nm}$ (Waters 484). The mobile phase consisted of $88 \% 20 \mathrm{mM}$ $\mathrm{Na}_{2} \mathrm{HPO}_{4} / \mathrm{NaH}_{2} \mathrm{PO}_{4}, 2 \mathrm{mM}$ NaEDTA, $0.2 \mathrm{M}$ triethylammonium chloride ( $\mathrm{pH} 6.6$ ) and $12 \%$ acetonitrile. Recovery of DFX and FX was respectively $>80 \%$ and al most $100 \%$. The detection limit for $F X$ was $0.25 \mathrm{nmol}$. I ron levels were based on $\mathrm{FX} / \mathrm{DFX}$ ratios from $\mathrm{FeSO}_{4}$ standards incubated and extracted as the samples. $\mathrm{Mn}^{2+}$ (100- to 800-fold excess) did not affect chelation of iron by DFX in this procedure.

Total iron in the resuspended pellet $(20 \% \mathrm{w} / \mathrm{v}$ in Tris/ $\mathrm{HCl}$ ) was determined using the iron(II) chelator Ferrozine essentially according to Riederer et al. (50). Briefly, samples were added with Ferrozine (4.2 mM ), ascorbic acid $(20 \mathrm{mg} / \mathrm{ml})$ to reduce iron, and pepsine $(0.1 \%)$ at a final $\mathrm{pH}$ of 2.5 using $\mathrm{HCl}$. Subsequently, samples were incubated at $37^{\circ} \mathrm{C}$ for $20 \mathrm{~min}$, and absorbances were read at $560 \mathrm{~nm}$. Blank and standard iron samples were treated in a similar manner. $\mathrm{Mn}^{2+}$ did not affect chelation of iron by Ferrozine.

\section{Statistics}

Changes of the differences between ipsi- and contralateral tissues over time or with increasing dose were statistically evaluated using ANOVA (BMDP Statistical Software program SOLO, Los Angeles) followed by Newman-Keuls multiple comparisons test. In addition, the effect of time or dose in contra- or ipsilateral striata were also tested. Differences between values of ipsiand contralateral tissues at the separate time points or doses were evaluated using Student's t test.

\section{RESULTS}

Time-Dependent Effects of $0.4 \mu \mathrm{mol} \mathrm{Mn}^{2+}$

SA levels expressed as [ipsi-/contralateral] ratios were significantly increased by $\mathrm{Mn}^{2+}$ at 6 (1.5-fold) and $18 \mathrm{~h}$ (1.9-fold), but not at $2 \mathrm{~h}$ (1.3 fold). Such increased SA levels by $\mathrm{Mn}^{2+}$ probably indicate a loss of local membrane integrity. To correct for differences in SA tissuelevels, DHBA levels are expressed as [DHBA/SA] (mmol adduct/mol SA) followed by calculations of [ipsi-/ contralateral ] ratios to determine the factor of increase by $\mathrm{Mn}^{2+}$. [I psi-/contralateral] ratios of [DHBA/SA] were significantly increased by $\mathrm{Mn}^{2+}$ over time $(P<0.001)$, reaching maximum levels at $6 \mathrm{~h}$ for both 2,3-DHBA (4.1-fold increase) and 2,5-DHBA (6.9-fold increase) and no significant increase between 0 and $2 \mathrm{~h}$ of 2,3-DHBA/SA ratios (Fig. 1).

DA levels (Fig. 1) were significantly decreased by $\mathrm{Mn}^{2+}$ at $2 \mathrm{~h}(-53 \%)$ and declined further thereafter until at least $18 \mathrm{~h}(-65 \%)$ compared to contralateral tissues $(P<0.001)$. Serotonin levels (Fig. 1) weresignificantly decreased $(-49 \%)$ by $\mathrm{Mn}^{2+}$ at $2 \mathrm{~h}$ and declined further thereafter reaching the lowest levels at $18 \mathrm{~h}$ ( $-73 \%$ of contralateral striatum).

DOPAC (1.7-fold) and HVA (1.5- to 1.7-fold) levels were significantly increased by $\mathrm{Mn}^{2+}$ at 2 and $6 \mathrm{~h}$ and were significantly decreased at $18 \mathrm{~h}(-40 \%$ and $-65 \%$ of contralateral striatum, respectively). The resulting DA turnover expressed as DOPAC/DA and HVA/DA ratios was significantly elevated at $2 \mathrm{~h}$ (3.3- and 2.8-fold, respectively) and declined thereafter until a still-significant increase of DOPAC/DA ratios (1.6-fold of contralateral) and normal HVA/DA ratios at $18 \mathrm{~h}$ (Fig. 2). 5-HIAA levels were significantly decreased $(-39 \%)$ by $\mathrm{Mn}^{2+}$ at $2 \mathrm{~h}$ and declined further thereafter until $-69 \%$ of contralateral tissue at $18 \mathrm{~h}$. The resulting 5-HIAA/5-HT ratios were slightly, but significantly, elevated by $\mathrm{Mn}^{2+}(\mathrm{P}<0.001)$, but did not change between 2, 6, and $18 \mathrm{~h}$ (Fig. 2).

In noninjected (contralateral) striatum, the means \pm SEM of 2,3- and 2,5-DHBA/SA values and DA, 5-HT, 

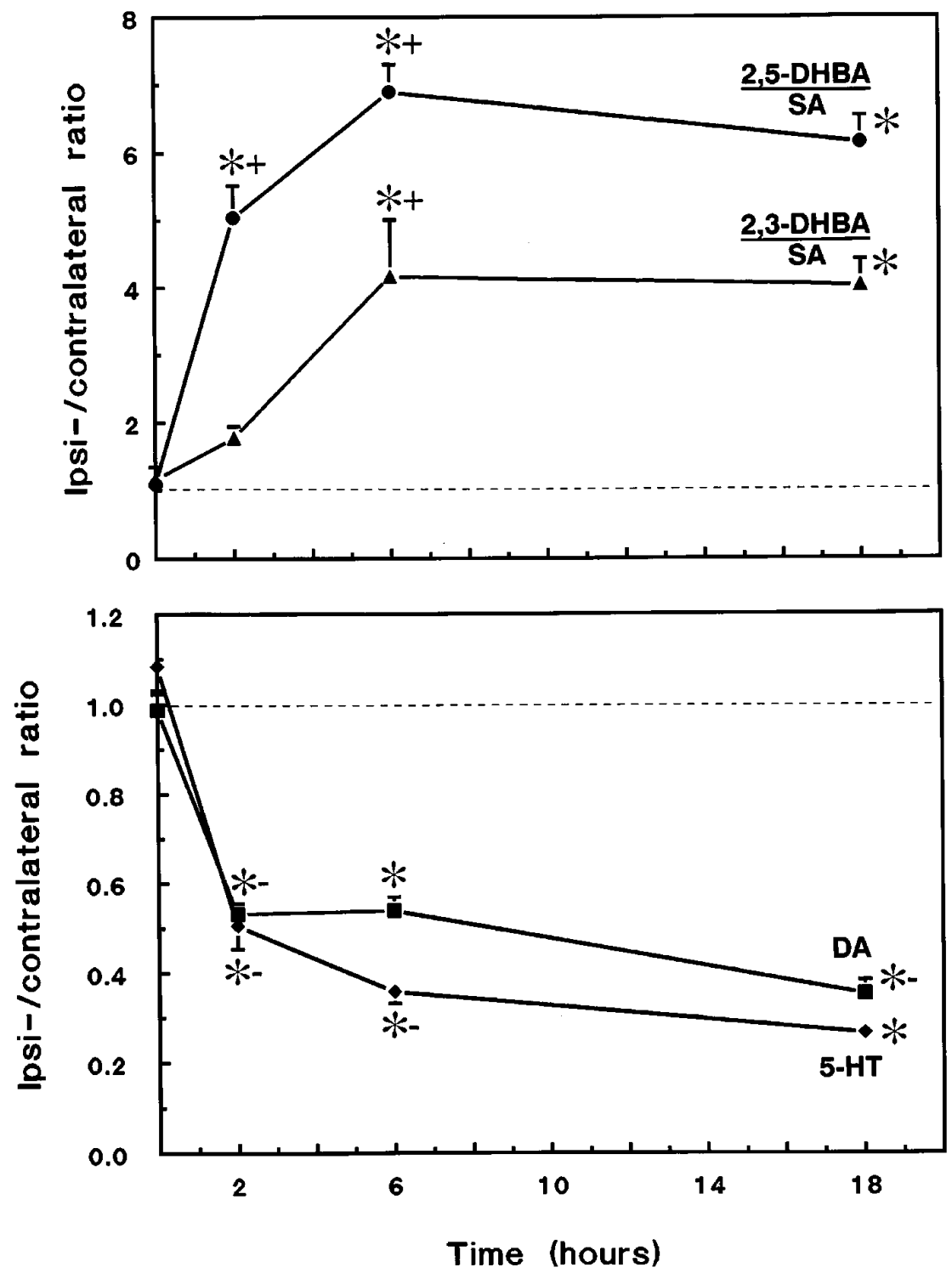

FIG. 1. Time course of 2,3- (triangles) and 2,5-DHBA (circles) formation corrected for SA (top) and of dopamine (squares) and serotonin (diamonds) depletion (bottom) in striatum following a unilateral injection of $0.4 \mu \mathrm{mol} \mathrm{Mn}^{2+}$ into striatum of SA-loaded rats ( $300 \mathrm{mg} / \mathrm{kg} \mathrm{ip} ; 2 \mathrm{~h}$ ). Data represent ipsi-/contralateral ratios of 6-7 rats per time point. All compounds changed time-dependently $(P<0.001, A N O V A)$. Newman-Keuls post hoc multiple comparison tests $(\alpha=0.05)$ indicated significant changes between subsequent data time points $(+/-)$ and compared to zero time points (asterisks). The zero time points represent noninjected controls (treated only with SA). For comparison with $\mathrm{Mg}^{2+}$-injected controls at $6 \mathrm{~h}$ see Fig. 3.

DOPAC, HVA, and 5-HIAA levels were respectively $0.30 \pm 0.033$ and $2.03 \pm 0.11 \mathrm{mmol} / \mathrm{mol} \mathrm{SA}$ and $68.9 \pm$ $1.43,3.15 \pm 0.08,5.16 \pm 0.16,4.71 \pm 0.16$, and $4.38 \pm$ $0.08 \mathrm{pmol} / \mathrm{mg}$, except at $2 \mathrm{~h}$ where levels of DA, DOPAC, and HVA were significantly elevated $(P<0.001)$. The latter effect is most likely dueto chloralhydrateanesthesia (Westerink, 1985).

\section{Dose-Dependent $\mathrm{Effects}$ of $\mathrm{Mn}^{2+}$ at $6 \mathrm{~h}$}

Six hours after intrastriatal injections of different doses of $\mathrm{Mn}^{2+}(0.13,0.4$, and $1.2 \mu \mathrm{mol})$, SA levels ex- pressed as [ipsi-/contralateral] ratios were significantly increased in a dose-dependent manner $(P<0.001)$ by respectively 1.2-, 1.5-, and 2.0-fold. The [ipsi-/contralateral] ratios of DHBA levels corrected for SA are shown in Fig. 3. [2,3-DHBA/SA] values were significantly increased by 0.4 and $1.2 \mu \mathrm{mol} \mathrm{Mn}^{2+}(\mathrm{P}<0.001)$, but not by $0.13 \mu \mathrm{mol} \mathrm{Mn}^{2+}$ or $0.4 \mu \mathrm{mol} \mathrm{Mg}^{2+}$. [2,5-DHBA/SA] values were significantly el evated by all doses, including a relatively small increase by the control injection with $\mathrm{Mg}^{2+}(+37 \%)$, which is probably dueto mechanical damage by the injection needle. Both 2,3- and 2,5- 
DHBA increases reached plateau levels by $0.4 \mu \mathrm{mol}$ $\mathrm{Mn}^{2+}$ (respectively 4.2- and 6.9-fold).

DA levels (Fig. 3) were significantly reduced by 0.13 $\mu \mathrm{mol} \mathrm{Mn}^{2+}(-15 \%)$, and dedined dose-dependently to $-87 \%$ by $1.2 \mu \mathrm{mol}$. Control injections with $\mathrm{Mg}^{2+}$ increased DA levels slightly, but significantly (+14\%; $P<0.05$ ). Serotonin levels (Fig. 3) were significantly reduced by $0.13 \mu \mathrm{mol} \mathrm{Mn}^{2+}(-55 \%)$ and dedined dosedependently until $-76 \%$ of contralateral tissues $(\mathrm{P}<0.001)$. Following $\mathrm{Mg}^{2+}$ injections, 5-HT levels were slightly, but significantly, decreased (-14\%; $\mathrm{P}<0.05)$.

DOPAC and HVA levels were significantly increased by $0.13 \mu \mathrm{mol} \mathrm{Mn}^{2+}$ (respectively 1.9- and 2.4-fold) and declined dose-dependently reaching levels of $-51 \%$ and $-32 \%$ at $1.2 \mu \mathrm{mol}$, respectively. $\mathrm{Mg}^{2+}$ injections increased DOPAC (+61\%) and HVA (+88\%) levels significantly $(P<0.001)$. The resulting DOPAC/DA and $\mathrm{HVA} / \mathrm{DA}$ ratios were significantly increased in a dosedependent manner $(P<0.01)$, reaching 4.9 - and 7.8fold elevations by $1.2 \mu \mathrm{mol} \mathrm{Mn}^{2+}$, respectively (Fig. 4). 5 -HIAA levels were significantly reduced by $0.13 \mu \mathrm{mol}$ $\mathrm{Mn}^{2+}(-41 \%)$ and declined dose-dependently until $-76 \%$ ( $\mathrm{P}<0.001)$. The resulting $5-\mathrm{HIAA} / 5-\mathrm{HT}$ ratios were not dose-dependently changed by $\mathrm{Mn}^{2+}(\mathrm{P}=0.32)$ (Fig. 4).

\section{Detection of 6-OHDA after $\mathrm{Mn}^{2+}$}

In $\mathrm{Mn}^{2+}$-injected striata of rats not loaded with SA, no peaks at the position of 6-OHDA standards were observed (data not shown).

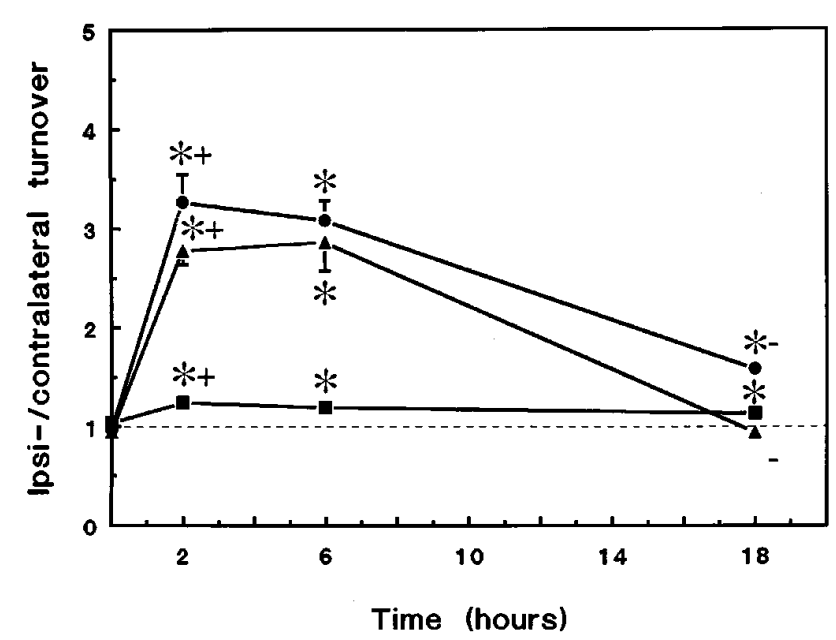

FIG. 2. Time course of dopamine and serotonin turnover following unilateral intrastriatal injection of $0.4 \mu \mathrm{mol} \mathrm{Mn}^{2+}$ into striatum of salicylate-loaded rats (300 mg/kg ip; $2 \mathrm{~h}$ ). Data represent [ipsi-/ contralateral] ratios of DOPAC/DA (circles), HVA/DA (triangles), and 5-HIAA/5-HT (squares) ratios of 6-7 rats per time point. The DA and 5 -HT turnover changed time-dependently (ANOVA, $\mathrm{P}<0.001$ ). For more details see legend to Fig. 1.
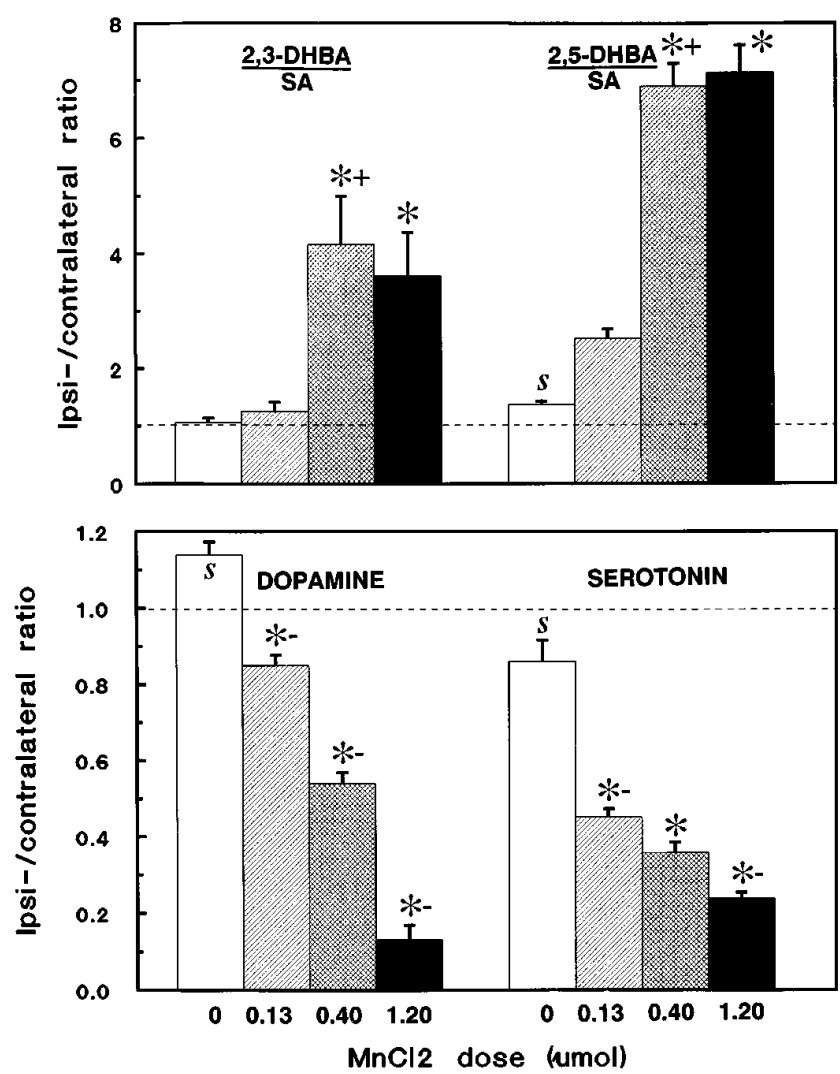

FIG. 3. Dose-dependent 2,3- and 2,5-DHBA formation corrected for SA (top), and dopamine and serotonin depletions (bottom) in striatum $6 \mathrm{~h}$ after a unilateral control $\left(\mathrm{Mg}^{2+}\right)$ or $\mathrm{Mn}^{2+}$ injection (dose as indicated) into striatum of SA-loaded rats. Data represent [ipsi-/ contralateral] ratios of 6-7 rats. All compounds changed dosedependently (ANOVA; $\mathrm{P}<0.001$ ). Newman-Keuls post hoc multiple comparison tests $(\alpha=0.05)$ revealed significant changes between subsequent dose points $(+/-)$ and compared to the 0 dose group (asterisk), which represents $\mathrm{Mg}^{2+}$ injections (with $0.4 \mu \mathrm{mol}$ ). S, significant difference between ipsi- and contralateral values using Student's t test ( $\mathrm{P}<0.05$, only indicated for the zero dose group).

\section{Effect of ReserpinePretreatment on Mn Neurotoxicity}

The striatal DA and 5-HT contents of rats pretreated with reserpine were depleted by 89 and $56 \%$, respectively. In reserpine-treated rats, $\mathrm{Mn}^{2+}$ injections did not significantly decrease DA levels any further compared to contralateral tissues ( $P=0.39$ by Student's t test, Fig. 5) in contrast to a significant further decrease of 5-HT levels until -76\%. 2,3-DHBA/SA ratios were significantly higher $(P<0.001)$ in both noninjected (2.1-fold) and $\mathrm{Mn}^{2+}$-injected striata (1.7-fold) of reserpine-treated rats compared to striata of control rats (Fig. 5). A similar significant effect for 2,5-DHBA/SA was observed in this respect (respectively 1.9- and 1.9-fold). The $\mathrm{Mn}^{2+}$-induced 2,3-DHBA formation (expressed as ipsi-/contralateral ratios of DHBA/SA) in reserpine-treated rats (2.8-fold) was not significantly different from that in control rats (4.2-fold). The same 
was found for 2,5-DHBA formation in this respect (respectively 6.5- versus 6.9-fold).

\section{Effect of $\mathrm{Mn}^{2+}$ on Total and LMW Iron in Striatum}

Six hours after intrastriatal injection, $\mathrm{Mn}^{2+}$ produced no significant changes in striatal LMW or total iron pools compared to $\mathrm{Mg}^{2+}$ - or not-injected tissues (Table 1). Furthermore, striatal LMW iron levels of $\mathrm{Mn}^{2+}$ or $\mathrm{Mg}^{2+}$-injected rats were similar when measured under reducing or nonreducing conditions. In contrast, $6 \mathrm{~h}$ after intrastriatal $\mathrm{Fe}^{2+}$-injection, both LMW and total iron pools in striatum were markedly increased. In addition, in these striata, under reducing conditions, about 15-fold more iron was chelated by DFX in the LMW pool than in physiological medium. This difference can be due to a fine ferric hydroxide precipitation.

\section{Effects of Deferoxamine on Mn Neurotoxicity}

Co-injections of $\mathrm{Mn}^{2+}$ with 0.2 or $2.0 \mathrm{nmol} \mathrm{DFX}$ into striatum did not significantly alter 2,3- (Table 2) or 2,5-DHBA/SA increases or the extent of DA depletions (Table 2) compared to $\mathrm{Mn}^{2+}$ injections without DFX. There were no significant effects of DFX in contralateral tissues. Differences between ipsi- and contralateral levels of 2,3-DHBA/SA, 2,5-DHBA/SA, and DA were highly significant in all tested groups $(P<0.001)$. The means \pm SEM of 2,3- and 2,5-DHBA $/ \mathrm{SA}(\mathrm{mmol} / \mathrm{mol}$ $\mathrm{SA}$ ) and DA levels (pmol/mg) after $\mathrm{NaCl}$ injection were respectively $0.40 \pm 0.03,2.1 \pm 0.24$, and $72.7 \pm 3.4$.

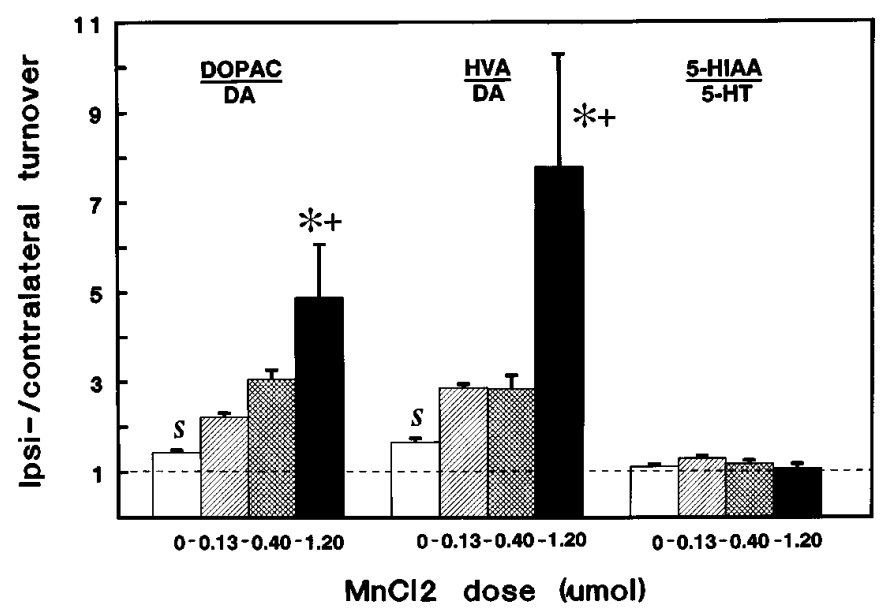

FIG. 4. Dose-dependent changes of dopamine and serotonin turnover $6 \mathrm{~h}$ after a unilateral control $\left(\mathrm{Mg}^{2+}\right)$ or $\mathrm{Mn}^{2+}$ injection (dose as indicated) into striatum of salicylate-loaded rats (300 mg/kg ip; 2 h). Data represent [ipsi-/contralateral] ratios of [metabolite/neurotransmitter] ratios of 6-7 rats. DA turnover changed dose-dependently (ANOVA; $\mathrm{P}<0.005$ for DOPAC/DA and $\mathrm{P}<0.01$ for HVA/DA), whereas the 5-HT turnover did not. For more details see legend to Fig. 3.
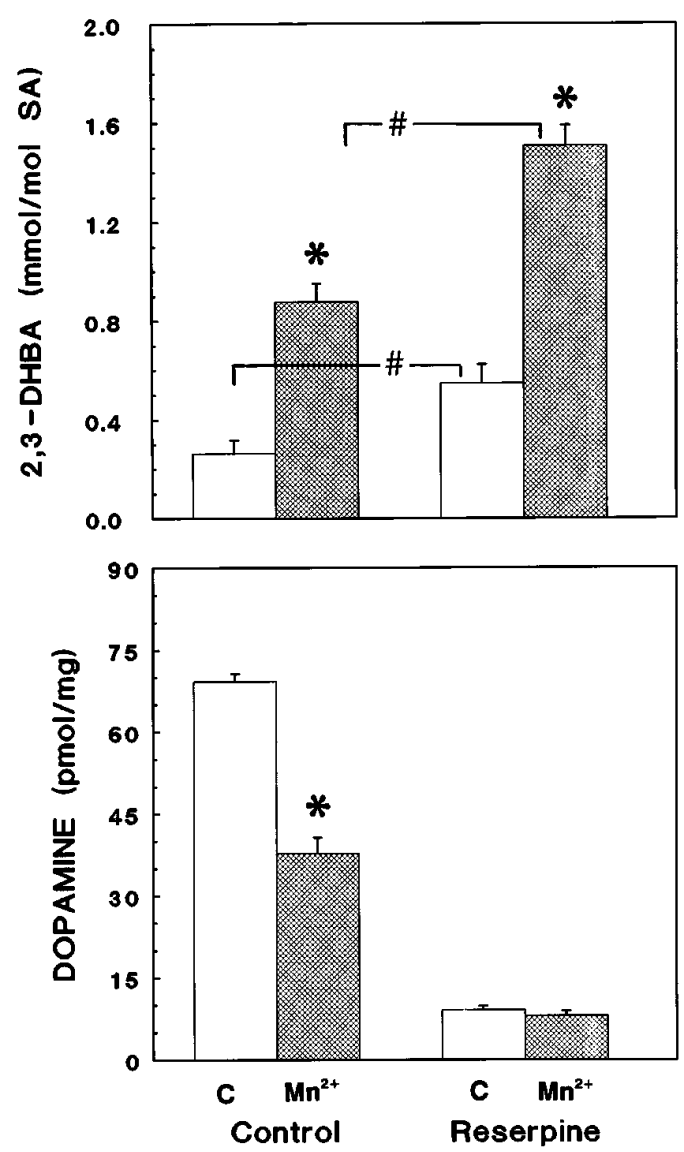

FIG. 5. Effect of pretreatment with reserpine ( $2.5 \mathrm{mg} / \mathrm{kg}$ ip; $24 \mathrm{~h}$ ) on 2,3-DHBA (mmol/mol SA; top) and dopamine levels (pmol/mg; (bottom) in striatum $6 \mathrm{~h}$ after unilateral injection of $0.4 \mu \mathrm{mol} \mathrm{Mn}^{2+}$ into striatum of SA-loaded rats (300 mg/kg ip; 2 h). Significant differences between $\mathrm{Mn}^{2+}$-injected (hatched bars) and noninjected contralateral striata (C, white bars) are indicated by asterisks (Student's t test; $\mathrm{P}<0.001$ ). Both basal 2,3-DHBA/SA (noninjected side) and increased 2,3-DHBA/SA by $\mathrm{Mn}^{2+}$ were significantly higher in reserpine-treated rats than in control rats $(\#, P<0.001$ by Student's t test). However, the increases of 2,3-DHBA/SA (expressed as [ipsi-/contralateral] ratios) by $\mathrm{Mn}^{2+}$ between reserpine-treated (2.8-fold) and control rats (4.2-fold) were not significantly different ( $P=0.16$, Student's t test). DA levels (bottom) were significantly depleted by reserpine (not indicated, Student's t test; $P<0.001$ ).

\section{DISCUSSION}

The present studies using SA as a $\mathrm{OH}$-trapping agent demonstrate time- and dose-dependent $\mathrm{OH}$ formation by $\mathrm{Mn}^{2+}$ in the living brain. Furthermore, $\mathrm{Mn}$ does not catalyze the Haber-Weiss reaction in vivo. Additional experiments indicate that $\mathrm{Mn}^{2+}$-induced $\mathrm{OH}$ are not generated as a result of DA oxidation nor by an increase in (free) chelatable endogenous iron.

Pronounced increases of 2,3-DHBA/SA ratios (up to 4-fold) in $\mathrm{Mn}^{2+}$-injected striatum compared to controls (Figs. 1 and 3) suggest that $\mathrm{Mn}^{2+}$ induces $\mathrm{OH}$ formation. In addition, our results indicate that $\mathrm{OH}$ are not triggered by $\mathrm{Mn}$ itself, because maximum levels are 
TABLE 1

Effect of Intrastriatal I njection of $0.4 \mu \mathrm{mol} \mathrm{Mn}^{2+}, \mathrm{Fe}^{2+}$, or $\mathrm{Mg}^{2+}$ (Controls) on Total Low (LMW)a or High Molecular

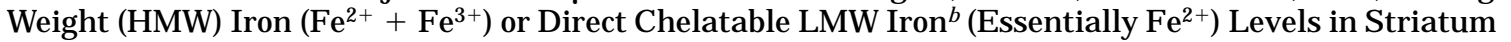
(pmol/mg wet wt) $6 \mathrm{~h}$ after Administration

\begin{tabular}{lccrr}
\hline & & & Total iron levels $\left(\mathrm{Fe}^{2+}+\mathrm{Fe}^{3+}\right)$ \\
\cline { 3 - 5 } $\begin{array}{l}\text { Intrastriatal } \\
\text { injection }\end{array}$ & $\begin{array}{c}\text { Direct chelatable } \\
\text { LMW ironb }\end{array}$ & LMWa & HMW & LMW + HMW \\
\hline $\begin{array}{l}\text { Noninjected } \\
\mathrm{MgCl}_{2}\end{array}$ & $\mathrm{ND}$ & $24 \pm 12(3)$ & $75 \pm 4(3)$ & $100 \pm 14(3)$ \\
$\mathrm{MnCl}_{2}$ & $53 \pm 11(4)$ & $39 \pm 11(3)$ & $76 \pm 5(7)$ & $118 \pm 16(3)$ \\
$\mathrm{FeCl}_{2}$ & $32 \pm 9(4)$ & $26 \pm 9(4)$ & $74 \pm 11(8)$ & $98 \pm 43(4)$ \\
\hline
\end{tabular}

Note Data are means \pm SEM of 3-10 samples (n). Determinations of $\mathrm{Mn}^{2+}{ }_{-}, \mathrm{Mg}^{2+}$, and noninjected striata are based on 2-4 pool ed tissues per sample. LMW and total iron levels in $\mathrm{Mn}^{2+}$-injected striata were not significantly different from $\mathrm{Mg}^{2+}$ - or noninjected tissue. LMW iron determined under bphysiological or areducing conditions (for details see Materials and Methods) were not significantly different in Mg2+- or $\mathrm{Mn}^{2+}$-injected striata. In Fe ${ }^{2+}$-injected striata, LMW and HMW iron pools were clearly increased. The difference between LMW iron levels assessed in physiological and reduced media of $\mathrm{Fe}^{2+}$-injected striata is probably due to a fine ferric hydroxide preci pitate. ND, not determined.

only reached after 6-18 $\mathrm{h}$. The time course of 2,3-DHBA formation after $\mathrm{Mn}^{2+}$ is very different from that after equimolar injections of $\mathrm{Fe}^{2+}$ into striatum, where highest increases of 2,3-DHBA (10-fold) were observed after $30 \mathrm{~min}$ (57). Therefore, the present findings suggest that $\mathrm{Mn}^{2+}$ cannot catalyze the Haber-Weiss reaction in vivo, which is supported by in vitro studies (1 and references therein, 30).

DA and 5-HT depletions in striatum by $\mathrm{Mn}^{2+}$ are time and dose-dependent and are not directly related to $\mathrm{OH}$ formation (Figs. 1 and 3 ). In contrast to DA and 5-HT levels, 2,3-DHBA formation (ipsi-/contralateral ratio of 2,3-DHBA/SA) was not significantly changed at $2 \mathrm{~h}$ and also did not change when the $\mathrm{Mn}^{2+}$-dose was increased from 0.4 to $1.2 \mu \mathrm{mol} \mathrm{Mn}^{2+}$. This independent action of $\mathrm{Mn}^{2+}$ on these two processes was in line with

\section{TABLE 2}

Effect of the I ron Chelator Deferoxamine $(0,0.2$, or $2.0 \mathrm{nmol}$ DFX) on $\mathrm{Mn}^{2+}$-I nduced $\mathrm{OH}$ Formation (2,3-DHBA/SA) and Dopamine Depletion $6 \mathrm{~h}$ after Co-injection of $0.4 \mu \mathrm{mol} \mathrm{Mn}^{2+}$ with DFX into the I psilateral Striatum or $0.4 \mu \mathrm{mol} \mathrm{NaCl}$ with DFX into the Contralateral Striatum of SA-loaded Rats (300 mg/kg ip; $2 \mathrm{~h}$ )

\begin{tabular}{lccc}
\hline & \multicolumn{3}{c}{$\begin{array}{c}\text { Intrastriatal co-injection of } \\
0.4 \mu \mathrm{mol} \mathrm{MN}^{2+} \text { and different } \\
\text { doses of deferoxamine (nmol) }\end{array}$} \\
\cline { 2 - 4 } $\begin{array}{c}\text { I psicontralateral } \\
\text { ratio }\end{array}$ & 0 & 0.2 & 2.0 \\
\hline 2,3-DHBA/SA & $1.92 \pm 0.12^{*}$ & $2.14 \pm 0.23^{*}$ & $1.85 \pm 0.06^{*}$ \\
Dopamine & $0.46 \pm 0.06^{*}$ & $0.47 \pm 0.02^{*}$ & $0.40 \pm 0.02^{*}$ \\
\hline
\end{tabular}

Note Data are means \pm SEM expressed as [ipsi-/contralateral] ratios of 5-6 rats per dose. DFX co-injections did not significantly change $\mathrm{Mn}^{2+}$-induced 2,3-DHBA increases or DA depletion (ANOVA). Differences of 2,3-DHBA/SA values and DA levels between ipsi- and contralateral striata were highly significant in the three groups. $* \mathrm{P}<0.001$. our subsequent studies with reserpine-treated rats. $\mathrm{Mn}^{2+}$-induced $\mathrm{OH}$ formation was not attenuated in the DA-depleted striatum (Fig. 5). Furthermore, in the reserpine-treated rat with $90 \%$ depletion of striatal DA, $\mathrm{Mn}^{2+}$ did not cause additional DA reduction. Thus, $\mathrm{Mn}^{2+}$-induced $\mathrm{OH}$ formation is independent of depletion cq. oxidation of $\mathrm{DA}$ by $\mathrm{Mn}^{2+}$. Indeed, in vitro studies on the mechanism of $\mathrm{Mn}^{2 / 3+}$-induced oxidation of DA revealed that DA is rapidly and irreversibly oxidized by $\mathrm{Mn}^{3+}$ to its cyclized orthoquinone, resulting in decreased levels of DA, but does not generate reactive oxygen species since oxygen is neither consumed nor required in this reaction $(1,51)$. In conclusion, a similar process seems to occur in vivo. The twofold elevation of basal $\mathrm{OH}$ production in striatum after reserpine treatment (Fig. 5) is in line with another study in which reserpine increased levels of oxidized GSH in striatum, an indication of oxidative stress (58).

It has been suggested that toxic quinones as a consequence of DA oxidation (by $\mathrm{Mn}$ ) may compomise cellular defense mechanisms against oxyradicals (51), for instance by GSH depletion $(26,27,38,43)$. Our results obtained at $6 \mathrm{~h}$ after $\mathrm{Mn}^{2+}$ in reserpine-treated rats do not support this hypothesis. However, an increase of oxidative stress by quinones, and therefore a role of DA in Mn neurotoxicity, cannot be ruled out at later time points.

The increased production of another reactive oxygen species, $\mathrm{H}_{2} \mathrm{O}_{2}$, due to enhanced enzymatic turnover of DA (DOPAC/DA and HVA/DA ratios), which has been hypothetically linked with oxidative stress $(14,58)$, does not parallel 2,3-DHBA formation after $\mathrm{Mn}^{2+}$ both in time (Fig. 2) and with increasing dose (Fig. 4). This indicates that not $\mathrm{H}_{2} \mathrm{O}_{2}$ production from enzymatic $D A$ oxidation, but other factors determine $\mathrm{OH}$ generation. In addition, the serotonin turnover was only slightly affected by $\mathrm{Mn}^{2+}$, indicating a different (initial) response of both types of neurons to $\mathrm{Mn}^{2+}$ exposure. 
Since $\mathrm{Mn}^{2+}$ itself cannot trigger $\mathrm{OH}$ formation, and the likely candidates DA and 6-OHDA-which we did not detect in vivo-cannot explain the observed increase of $\mathrm{OH}$ formation by $\mathrm{Mn}^{2+}$, the role of endogenous iron was also examined after $\mathrm{Mn}^{2+}$. However, in $\mathrm{Mn}^{2+}$ injected striatum LMW iron, which is considered a relevant pool for catalyzing the Haber-Weiss reaction (36), was not different from that in $\mathrm{Mg}^{2+}$ - or noninjected striata (Table 1). Results obtained in $\mathrm{Fe}^{2+}$-injected striata indicated that our assay procedures worked. Thus, "free" or LMW iron does not participate in $\mathrm{Mn}^{2+}$-induced $\mathrm{OH}$ formation unless (very) local increases play a role. Ther efore intrastriatal co-injections of $\mathrm{Mn}^{2+}$ with the iron chelator DFX were conducted using doses known to retard 6-OHDA neurodegeneration (7) and sufficient to chelate the measured LMW iron pool completely. However, different intrastriatal DFX injections could not attenuate $\mathrm{Mn}^{2+}$-induced 2,3DHBA formation (Table 2), which is consistent with our data on LMW iron. An important additional fact which supports the latter conclusion is that iron chelation by $\mathrm{DFX}$ in large excess of $\mathrm{Mn}^{2+}$ was not affected in vitro.

The question then arises, are there other mechanisms which may be responsible for $\mathrm{Mn}^{2+}$-induced $\mathrm{OH}$ ? We propose two other mechanisms. First, $\mathrm{Mn}^{2+}$ accumulates preferentially in mitochondria via the $\mathrm{Ca}^{2+}$ uniporter, thereby inhibiting its own and $\mathrm{Ca}^{2+}$ effluxes (24) and impairing several mitochondrial respiratory functions and GSH metabolism $(9,25,38,39)$. Under such conditions, disturbances of cytochrome heme metabolism $(38,49)$ and/or heme-associated electron transfers by $\mathrm{Mn}^{2+}$ may lead to oxoheme oxidants in the presence of $\mathrm{H}_{2} \mathrm{O}_{2}$ or the postulated heme-associated ferryl radicals $(18,28,29,48)$, which may cause SA hydroxylation in our studies (48). DFX can probably not chelate iron from heme proteins, and this may explain the lack of an effect of DFX on $\mathrm{Mn}^{2+}$-induced $\mathrm{OH}$.

Recently, protection has been shown by NO-synthase inhibitors after brain injury by some mitochondrial toxins (52). Since $\mathrm{Mn}^{2+}$ also acts like a mitochondrial toxin that may raise $\mathrm{NO}, \mathrm{OH}$ may be derived from the decomposition of peroxynitrite, which is a reaction product of $\mathrm{NO}$ and $\mathrm{O}_{2}^{-{ }^{-}}(5,15,37,34)$.

In conclusion, selective regional accumulation of $\mathrm{Mn}^{2+}$ in the basal ganglia and its preferential sequestration in mitochondria may lead to local oxyradical formation and mitochondrial dysfunctions, which eventually result in sel ective cell death. The present studies have shown that DA and chelatable iron do not contribute to $\mathrm{Mn}^{2+}$-induced $\mathrm{OH}$. Therefore, other mechanisms explaining oxidant stress after $\mathrm{Mn}^{2+}$ intoxication such as site-specific $\mathrm{OH}$ formation through mitochondrial heme-iron moieties or peroxynitrite formation should bestudied. An additional role of DA quinones in producing oxidative stress remains to be elucidated.

\section{ACKNO WLEDG MENTS}

This work was partially financed by The Netherlands Ministry of Education and Sciences. The authors thank the late Dr. D. C. J . Poortvliet for statistical analyses.

\section{REFERENCES}

1. ARChibald, F. S., AND C. Tyree. 1987. Manganese poisoning and the attack of trivalent manganese upon catecholamines. Arch. Biochem. Biophys. 256: 638-650.

2. AsChner, M., AND J . L. AsChner. 1991. Manganese neurotoxicity: Cellular effects and blood-brain barrier transport. Neurosci. Biobehav. Rev. 15: 333-340.

3. Barbeau, A., N. Inoue, and T. Cloutier. 1976. Role of manganese in dystonia. Adv. Neurol. 14: 339-352.

4. Barbeau, A. 1984. Manganese and extrapyramidal disorders (A critical review and tribute to Dr. George C. Cotzias). Neurotoxicology 5: 13-36.

5. Beckman, J. S., T. W. Beckman, J. Chen, P. M. Marshall, and B. A. FREEMAN. 1990. Apparent hydroxyl radical production from peroxynitrite: Implications for endothelial injury by nitric oxideand superoxide. Proc. Natl. Acad. Sci. USA 87: 1620-1624.

6. BENKOVIC, S. A., AND J . R. CONNOR. 1993. Ferritin, transferrin, and iron in selected regions of the adult and aged rat brain. J . Comp. Neurol. 338: 97-113.

7. Ben-Sachar, D., G. Eshel, J. P. M. Finberg, and M. B. H. YoudIM. 1991. The iron chelator desferrioxamine (Desferal) retards 6-hydroxydopamine-induced degeneration of nigrostriatal dopamine neurons. J . Neurochem. 56: 1441-1444.

8. BiRd, E. D., A. H. Anton, And B. Bullock. 1984. The effect of manganese inhalation on basal ganglia dopamine concentrations in rhesus monkey. Neurotoxicol ogy 5: 59-66.

9. Brouillet, E. P., L. Shinobu, U. McGarvey, F. Hochberg, and F. BEAL. 1993. Manganese injection into the rat striatum produces excitotoxic lesions by impairing energy metabolism. Exp. Neurol. 120: 89-94.

10. Callaway, C. W., R. Kuczenski, and D. S. Segal. 1989. Reserpine enhances amphetamine stereotypes without increasing amphetamine-induced changes in striatal dialysate dopamine. Brain Res. 505: 83-90.

11. Cavallini, L., M. Valente, and A. Bindoli. 1984. On the mechanism of inhibition of lipid peroxidation by manganese. Inorg. Chim. Acta 91: 117-120.

12. Cohen, G., AND R. E. HeIkKILA. 1974. The generation of hydrogen peroxide, superoxide radical and hydroxyl radical by 6-hydroxydopamine, dialuric acid and related cytotoxic agents. J . Biol. Chem. 249: 2447-2452.

13. Cohen, G. 1984. Oxy-radical toxicity in catecholamine neurons. Neurotoxicology 5: 77-82.

14. Cohen, G., AND M. B. SpinA. 1989. Deprenyl suppresses the oxidant stress associated with increased dopamine turnover. Ann. Neurol. 26: 689-690.

15. Darley-Usmar, V. M., N. Hogg, V. J . O'Learly, M. T. Wilson, AND S. MONCADA. 1992. The simultaneous generation of superoxide and nitric oxide can initiatelipid peroxidation in human low density lipoprotein. FreeRadical Res. Commun. 17: 9-20.

16. Donaldson, J ., D. McGregor, And F. LabelLA. 1982. Manganese neurotoxicity: A model for free radical mediated neurodegeneration? Can. J . Physiol. Pharmacol . 60: 1398-1405.

17. DonALDSON, J . 1987. The physiopathologic significance of manganese in brain: I ts relation to schizophrenia and neurodegenerative disorders. Neurotoxicol ogy 8: 451-462.

18. DYKENS, J . A. 1994. I solated cerebral and cerebellar mitochon- 
dria produce free radicals when exposed to elevated $\mathrm{Ca}^{2+}$ and $\mathrm{Na}^{+}$: I mplications for neurodegeneration. J . Neurochem. 63: 584-591.

19. ERIKSSON, H., K. MäGista, L-O. Plantin, F. Fonnum, K-G. Hedström, E. Theodorsson-Norheim, K. Kristensson, E. StålBERG, AND E. HEILBRONN. 1987. Effects of manganese oxide on monkeys as revealed by a combined neurochemical, histological and neurophysiological evaluation. Arch. Toxicol . 61: 46-52.

20. Eriksson, H., P-G. Gillberg, S-M. Aquilonius, K-G. Hedström, And E. Heilbronn. 1992. Receptor alterations in manganese intoxicated monkeys. Arch. Toxicol. 66: 359-364.

21. Eriksson, H., J. Tedroff, K-A. Thuomas, S-M. Aquilonius, P. HaRTVIG, K-J . FASTh, P. BJ URLING, B. LÅngström, K-G. HedströM, AND E. HeILbRonn. 1992. Manganese induced brain lesions in Macaca fascicularis as revealed by positron emission tomography and magnetic resonance imaging. Arch. Toxicol. 66: 403-407.

22. Filloux, F., AND J . J. Townsend. 1993. Pre- and postsynaptic neurotoxic effects of dopamine demonstrated by intrastriatal injection. Exp. Neurol. 119: 79-88.

23. Garner, C. D., AND J . P. NAChtman. 1989. Manganese catalyzed auto-oxidation of dopamine to 6-hydroxydopamine in vitro. Chem.-Biol. Interact. 69: 345-351.

24. Gavin, C. E., K. K. Gunter, And T. E. Gunter. 1990. Manganese and calcium efflux kinetics in brain mitochondria. Relevance to manganese toxicity. Biochem. J . 266: 329-334.

25. Gavin, C. E., K. K. Gunter, and T. E. Gunter. 1992. Mn²+ sequestration by mitochondria and inhibition of oxidative phosphorylation. Toxicol. Appl. Pharmacol. 115: 1-5.

26. Graham, D. G., S. M. Tiffany, W. R. Bell J R., and W. F. GUTKNECHT. 1978. Autoxidation versus covalent binding of quinones as the mechanism of toxicity of dopamine, 6-hydroxydopamine, and related compounds toward C 1300 neuroblastoma cells in vitro. Mol. Pharmacol. 14: 644-653.

27. Graham, D. G. 1984. Catecholamine toxicity: A proposal for the molecular pathogenesis of manganese neurotoxicity and Parkinson's disease. Neurotoxicology 5: 83-96.

28. GRISHAM, M. B. 1985. Myoglobin-catalyzed hydrogen peroxide dependent arachidonic acid peroxidation. J . Free Radical Biol. Med. 1: 227-232.

29. Grisham, M. B., AND J. M. MCCORD. 1986. Chemistry and cytotoxicity of reactive oxygen metabolites. Pages 1-18 in A. E. Taylor, S. Matalon, and P. Ward, Eds., Physiology of Oxygen Radicals. Waverly Press, Baltimore.

30. Halliwell, B. 1984. Manganese ions, oxidation reactions and the superoxide radical. Neurotoxicol ogy 5: 113-118.

31. HalliwelL, B. 1992. Reactive oxygen species and the central nervous system. J. Neurochem. 59: 1609-1623.

32. HILL, J. M., AND R. C. SWITZER. 1984. The regional distribution and cellular localization of iron in the rat brain. Neuroscience 11: $595-603$.

33. HILL, J. M. 1990. Iron and proteins of iron metabolism in the central nervous system. Pages 315-330 in P. Ponka, H. M. Schulman, and R. C. Woodworth, Eds., Iron Transport and Storage CRC Press, Boca Raton, FL.

34. Hammer, B., W. D. Parker J R., And J. P. Bennett J R. 1993. NMDA receptors increase $\mathrm{OH}$ radicals in vivo by using nitric oxide synthase and protein kinase C. NeuroReport 5: 72-74.

35. Ingelman-Sundberg, M., H. Kaur, Y. Terelius, and B. HalliWELL. 1991. Hydroxylation of salicylate by microsomal fractions and cytochrome P-450: Lack of production of 2,3-dihydroxybenzoate unless hydroxyl radical is permitted. Biochem. J . 276: 753- 757.
36. Koster, J. F., AND W. Sluiter. 1994. Physiological relevance of free radicals and their relation to iron. Pages 409-427 in $\mathrm{H}$. Nohl, H. Esterbauer, and C. Rice-Evans, Eds., Free Radicals in the Environment, Medicine and Toxicology. Richelieu Press, London.

37. Lafon-Cazal, M., S. Pietri, M. Culcasi, and J . Bockaert. 1993. NMDA-dependent superoxide production and neurotoxicity. Nature 364: 535-537.

38. LICCIONE, J . J ., AND M. D. MAINES. 1988. Selective vulnerability of glutathione metabolism and cellular defense mechanisms in rat striatum to manganese. J . Pharmacol. Exp. Ther. 247: 156-161.

39. LICCIONE, J . L., AND M. D. MaInES. 1989. Manganese-mediated increase in the rat brain mitochondrial cytochrome P-450 and drug metabolism activity: Susceptibility of the striatum. J . Pharmacol. Exp. Ther. 248: 222-228.

40. Lista, A., J. Abarca, C. Ramos, and A. J. Daniels. 1986. Rat striatal dopamine and tetrahydrobiopterin content following an intrastriatal injection of manganese chloride. Life Sci. 38: 2121-2127.

41. London, R. E., G. Toney, S. A. Gabel, and A. Funk. 1989. Magnetic resonance imaging studies of the brains of anesthetized rats treated with manganese chloride. Brain Res. Bull. 23: 229-235.

42. Millar, D. M., G. R. Büttner, And S. D. Aust. 1990. Transition metals as catalysts of "autoxidation" reactions. Free Radical Biol. Med. 8: 95-108.

43. Monks, T. J ., R. P. Hanzlik, G. M. Cohen, D. Ross, and D. G. Graham. 1992. Contemporary issues in toxicology: Quinone chemistry and toxicity. Toxicol . Appl. Pharmacol. 112: 2-16.

44. Morris, C. M., J. M. Candy, A. B. Keith, A. E. Oakley, G. A. Taylor, R. G. L. Pullen, C. A. Bloxham, A. Gocht, and J. A. EDWARDSON. 1992. Brain iron homeostasis. J . Inorg. Biochem. 47: 257-265.

45. Newland, M. C., T. L. Ceckler, J . H. Kordower, and B. Weiss. 1989. Visualizing manganese in the primate basal ganglia with magnetic resonance imaging. Exp. Neurol. 106: 251-258.

46. Parenti, M., C. Flauto, E. Parati, A. Vescovi, and A. Groppetti. 1986. Manganese neurotoxicity: Effect of L-DOPA and pargyline treatments. Brain Res. 367: 8-13.

47. Parenti, M., L. Rusconi, V. Cappabianca, E. Parati, and A. GROPPETTI. 1988. Role of dopamine in manganese neurotoxicity. Brain Res. 473: 236-240.

48. Puppo, A., ANd B. Halliwell. 1988. Formation of hydroxyl radicals from hydrogen peroxide in the presence of iron. Is haemoglobin a biological Fenton reagent? Biochem. J. 249: 185-190.

49. QAto, M. K., AND M. D. Maines. 1985. Regulation of heme and drug metabolism activities in the brain by manganese. Biochem. Biophys. Res. Commun. 128: 18-24.

50. Riederer, P., E. Sofic, W-D. Rausch, B. Schmidt, G. P. ReyNOLdS, K. J ELLINGER, AND M. B. H. Youdim. 1989. Transition metals, ferritin, glutathione, and ascorbic acid in parkinsonian brains. J . Neurochem. 52: 515-520.

51. Segura-Aguilar, J., ANd C. Lind. 1989. On the mechanism of the $\mathrm{Mn}^{3+}$-induced neurotoxicity of dopamine: Prevention of quinonederived oxygen toxicity by DT diaphorase and superoxide dismutase. Chem.-Biol. I nteract. 72: 309-324.

52. Schulz, J. B., R. T. Matthews, D. R. Henshaw, and M. F. Beal. 1994. Inhibition of neuronal nitric oxide synthase (NOS) protects against neurotoxicity produced by 3-nitricpropionic acid, malonate and MPTP. Abstr. Soc. Neurosci. 20: 675.9. 
53. Shukla, G. S., AND V. C. Chandra. 1981. Manganese toxicity: Lipid peroxidation in rat brain. Acta Pharmacol. Toxicol. 48: 95-100.

54. Sloot, W. N., A. J . van der Sluij S-Gelling, and J -B. P. GramsBERGEN. 1994. Selective lesions by manganese and extensive damage by iron after injection into rat striatum or hippocampus. J . Neurochem. 62: 205-216.

55. Sloot, W. N., And J -B. P. Gramsbergen. 1994. Axonal transport of manganese and its relevance to selective neurotoxicity in the rat basal ganglia. Brain Res. 657: 124-132.

56. Sloot, W. N., And J -B. P. Gramsbergen. 1995. Detection of salicylate and its hydroxylated adducts 2,3- and 2,5-dihydroxybenzoic acids as possible indices for in vivo hydroxyl radical formation in combination with catechol- and indoleamines and their metabolites in cerebrospinal fluid and brain tissue. J . Neurosci. Methods, 60: 141-149.

57. Sloot, W. N., J. Korf, and J -B. P. Gramsbergen. 1995. In vivo hydroxyl radical formation by iron as determined by salicylate hydroxylation precedes dopamine and serotonin depletion in rat striatum. Pages 141-157 in W. N. Sloot, Ph.D. thesis, Oxidative Stress and Vulnerability of the Basal Ganglia University of Groningen, The Netherlands.

58. SPInA, M. B., AND G. Cohen. 1989. Dopamine turnover and glutathione oxidation: I mplications for Parkinson disease. Proc. Natl. Acad. Sci. USA 86: 1398-1400.

59. SUÁREZ, N., AND H. ERIKSSON. 1993. Receptor-mediated endocytosis of a manganese complex of transferrin into neuroblastoma (SHSY 5Y) cells in culture. J . Neurochem. 61: 127-131.

60. TAMPO, Y., AND M. YonAHA. 1992. Antioxidant mechanism of $\mathrm{Mn}(\mathrm{II})$ in phospholipid peroxidation. FreeRadical Biol. Med. 13: 115- 120.

61. Voogd, A., W. Sluiter, H. G. van Eij K, and J . F. Koster. 1992. Low molecular weight iron and the oxygen paradox in isolated rat hearts. J . Clin. Invest. 90: 2050-2055.

62. Wolters, E.Ch., C-C. Huang, C. Clark, R. F. Peppard, J . Okada, N-S. Chu, M. J . Adam, T. J . Ruth, D. Li, and D. B. Calne. 1989. Positron emission tomography in manganese intoxication. Ann. Neurol. 26: 647-651.

63. Yamada, M., S. Ohno, I. Okayasu, S. Hatakeyama, H. Watanabe, K. USHIO, AND H. TSUKAGOSHI. 1986. Chronic manganese poisoning: A neuropathological study with determination of manganese distribution in the brain. Acta Neuropathol. (Berlin) 70: 273-278.

64. Paxinos, G., AND C. WATSON. 1986. The Rat Brain in Stereotaxic Coordinates, 2nd ed. Academic Press, London.

65. WeStERINK, B. H. C. 1985. Sequence and significance of dopamine metabolism in the rat brain. Neurochem. Int. 7: 221-227. 